\title{
A MEDICALIZAÇÃO DA FORÇA DE TRABALHO: A INSTITUIÇÃO DE UM MODELO DE SAÚDE ATRAVÉS DA PUBLICIDADE NA DÉCADA DE 1930
}

THE MEDICALIZATION OF THE WORKFORCE: THE ESTABLISHMENT OF A HEALTH MODEL THROUGH ADVERTISING IN THE 1930S

Gabriel Kenzo Rodrigues*
gabrielk.rod@gmail.com

RESUMO: A implantação de um ideal racional-cientificista, para o trabalhador urbano paulista nas primeiras décadas do século XX, ocorreu consoante a uma alteração na representação de saúde, que deveria refletir o corpo saudável em termos de produtividade. Muitos laboratórios farmacêuticos passaram a produzir uma publicidade que estabelecesse interlocução com estas exigências, apresentando os medicamentos como os produtos que garantiriam a permanência do trabalhador no âmbito da competividade urbana acirrada, mantendo, desta forma, a possibilidade de venda de sua força de trabalho no mercado.

PALAVRAS-CHAVE: História da saúde, publicidade e propaganda, administração científica do trabalho.

ABSTRACT: The implementation of a rational and scientific model, for the urban worker in the early 20th of São Paulo city, ocurred along modifications on the representation of health, that should reflect the healthy body in terms of productivity. Many pharmaceutical laboratories began to produce advertisement capable to convey these new demands, displaying their medicines as the products that could assure the worker's stability in their field of work. Once the competition increased in the city of São Paulo, the communication delivered the idea that the worker would be able to keep himself in the market, as long as the products were consumed.

KEYWORDS: History of health, advertising and marketing, scientific management.

Ao longo de todo o século XX podemos observar a aplicação prática, cada vez mais incisiva no cotidiano dos trabalhadores, daqueles ideais inicialmente promulgados por Henri Fayol, e posteriormente por Frederick Taylor e Henry Ford, respectivamente. A decomposição dos movimentos em microgestos quantificados e esquadrinhados, para uma

\footnotetext{
${ }^{*}$ Mestre em História Social pela PUC-SP.
} 
divisão sistemática da força de trabalho, não apenas racionaliza a produção, mas fragmenta e cinde a unidade e a comunicação entre os trabalhadores dentro do ambiente de trabalho. Uma adequação do corpo humano à máquina, e vice-versa, limita os movimentos feitos pelas mãos trabalhadoras, como também absorve o restante dos sentidos em uma exigência de concentração total que rompe elos com tudo aquilo que se encontra à sua volta. Entretanto, a corporeidade nunca se anula, seus efeitos são demonstrados cedo ou tarde nesta união entre corpo e máquina.

As calorias que são gastas em um determinado processo de trabalho passam a ser mensuradas quando o corpo começa a ser visto em uma funcionalidade produtiva semelhante à máquina que ele opera, portanto, o calor que um corpo despende para realizar um trabalho ou a combustão corporal que proporciona em termos de energia para produção, são quantificados para que se estabeleça um padrão de gasto de energia de acordo com a profissão, um limador de ferro "queima" um número maior de calorias, do que uma datilógrafa (VIGARELLO, 2007, p. 19).

Até o final do século XIX e meados do XX, esta ideia de um corpo máquina perdura, alterando-se logo no período que se segue, especialmente a partir de 1920, quando são efetivamente os gestos e os micromovimentos que passam a ser metrificados pela regra científica de ordenação do trabalho. Assim, como Georges Vigarello bem exemplifica:

É o fim das charretes, movidas à força braçal, das manivelas, dos talhadores ou operários de alavancas, dos "levantadores" ou dos "carregadores", mas o início do ajustamento das peças dispostas sobre a cadeia produtiva, a montagem dos objetos organizados na mesma bancada, a sincronização de pequenos movimentos realizados na posição sentada diante de um posto claramente organizado (ibid., p. 20).

A padronização dos movimentos resultante do processo de linha de montagem embora a "força braçal", obviamente não desapareça -, acaba por conter a dissipação de calor em um reduto limitado e repetitivo, tornando desnecessária esta concepção de força de trabalho focada no gasto excessivo de calorias. Com isso, o modelo taylorista pretendia eliminar os conflitos entre classes e implantar os ideais de competitividade, individualismo e sobriedade nas indústrias. 
Em São Paulo, estes princípios são trazidos pelo empresário Roberto Simonsen, logo após o término da Primeira Guerra, ${ }^{1}$ em um contexto de crise econômica e tensões insurgentes entre a classe patronal e os trabalhadores.

Na medida em que a organização racional do trabalho lavrava um ideal neutro e objetivo para incremento da produção, a divisão sectária dos trabalhadores em funções específicas aparecia como uma forma pretensamente impessoal de desfragmentação das relações dentro do ambiente fabril, ocorrendo então uma substituição de uma disciplina próxima de um modelo militar para uma disciplina científica. A determinação de elementos do cotidiano fabril a partir de uma lógica cientificista - como o cálculo do salário, dos horários, salubridade trabalhista, condições de trabalho etc. -, propicia um distanciamento da realidade histórico-cultural do trabalhador e inserção destes elementos em uma predeterminação científica que busca impossibilitar as exigências por alterações.

Conforme aponta a historiadora Maria Antonieta Antonacci, este processo de disciplinarização científica, através da doutrina taylorista e fordista, não encontrou terreno apenas nas relações trabalhistas, mas contribui para reconfigurar as relações "dentro e fora dos muros das fábricas, recolocando agudamente questões em torno da educação, saúde, habitação, higiene, assistência, lazer etc." (1993, p. 61).

A institucionalização e o início da aplicação prática deste modelo de regimento organizacional estão centrados na criação do Instituto de Organização Racional do Trabalho (IDORT), fundado em São Paulo, no ano de 1931. Este era um órgão mantido pelo capital privado, inicialmente pelo jornal $O$ Estado de São Paulo, com a direção de grupos empresariais e um corpo de técnicos ${ }^{2}$. Tinha como propósito a consultoria para todo tipo de instituição, privada ou pública, que buscasse programar uma organização baseada nos princípios tayloristas e fordistas no seu cotidiano de trabalho. Concomitantemente à criação do IDORT têm-se a fundação da FIESP, SENAI, ABNT, Fundação Getúlio Vargas, Escola Livre de Sociologia e Política, e outras instituições ligadas à burguesia industrial que

\footnotetext{
${ }^{1}$ Após a Primeira Guerra, tanto o modelo europeu de "ciência do trabalho" quanto o taylorismo americano, ganham uma ampla visibilidade e passam a ser estudados e aprimorados por fisiologistas e psicólogos do trabalho. Ao longo da década de 1920, a nova geração de "administradores científicos" do trabalho, aplicam o controle racional de forma mais ampla, e ao mesmo tempo minuciosa, tendo em vista o desenvolvimento em campos como higiene industrial, estudo da monotonia e trabalho repetitivo, psicotécnica, testes de aptidão, treinamento personalizado para diferentes funções, conselho vocacional etc. Isto torna-se possível por conta da fusão das diferentes correntes administrativas europeias e americanas, as primeiras baseadas nos estudos de Fayol e Bédaux, enquanto as segundas, influenciadas sobretudo por Taylor e Ford (Cf. RABINBACH, 1992).

${ }^{2}$ Entre os seus principais idealizadores destacam-se o próprio Roberto Simonsen, o médico psiquiatra Antônio Carlos de Pacheco e Silva, o empresário Armando Salles de Oliveira, o engenheiro Roberto Mange e o médico Moacyr Álvaro.
} 
buscam na aplicação dos princípios racionais a reconfiguração da dinâmica da disciplina social.

Figura 1:

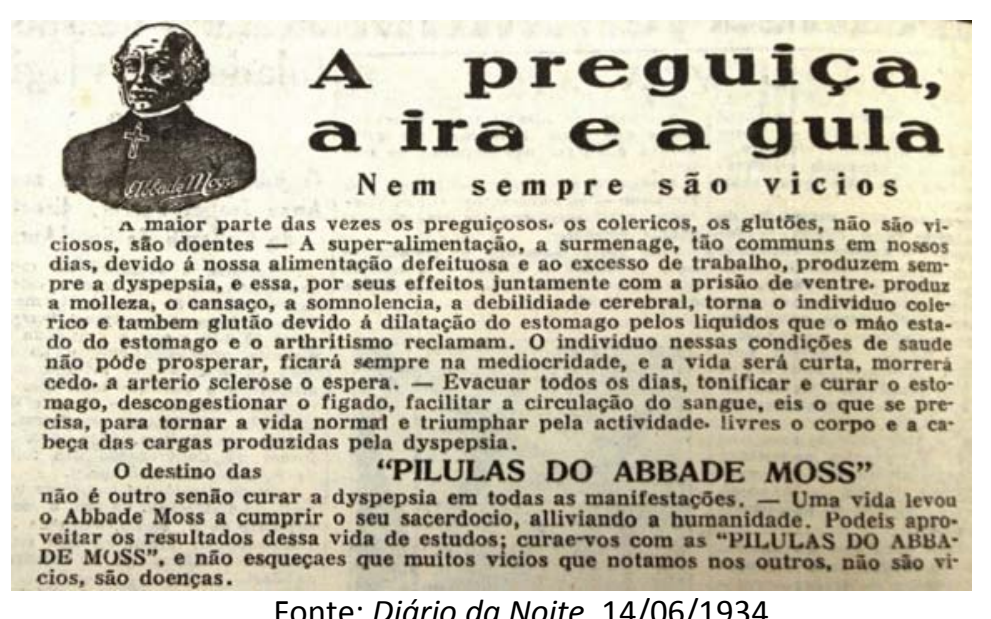

Fonte: Diário da Noite, 14/06/1934.

O trecho do discurso abaixo, proferido por Francisco de Salles Oliveira, diretor técnico da primeira divisão do IDORT e pai de Armando Salles, demonstra a preocupação dos idortianos em relação à configuração administrativa da sociedade como um todo:

E' a organização administrativa de um pais, em ultima analyse, o padrão pelo qual se afere o grau de seu desenvolvimento, quer sob o ponto de vista moral, quer intelectual, quer de produção. Nessa organização, mais do que em qualquer outra, torna-se necessario que todos os serviços funccionem harmonicamente e se completem e entrozem como se fossem peças de um machinismo $(1937$, p. 16).

A disciplinarização racional, portanto, ultrapassa o plano fabril e torna-se necessária em todos os âmbitos da sociedade, para um pleno funcionamento harmônico - como o mecanicismo clássico cartesiano supunha no século $\mathrm{XVII}^{3}$ - de todas as partes que compõem o todo social.

\footnotetext{
${ }^{3}$ Conforme aponta Jean-Jacques Courtine: “o surgimento progressivo de um imaginário mecânico do corpo com a difusão das concepções cartesianas rasga pouco a pouco a simbiose do organismo com o macrocosmo,
} 
Este modelo acaba por renovar o elogio ao trabalho em um novo contexto de industrialização, avanço científico e urbanização, típicos das décadas de 1920 e 1930 . Assim, um novo tipo de trabalhador passa a ser requerido, e características como agilidade, atenção, obediência devem ser ensinadas aos novos trabalhadores, pelas recém-criadas instituições que surgem ao serviço da burguesia patronal. A atitude filantrópica, as grandes doações, construções de hospitais, bibliotecas e outros feitos de caridade das elites, esmorecem na medida em que surgem as instituições, que ensinam a trabalhar "corretamente", como modelo de auxílio à classe trabalhadora, segundo os princípios racionais que devem combater a qualquer custo os fatores que impedem ou atrasam o desenvolvimento produtivo do país, como o ócio, a preguiça, a vagabundagem e o mau trabalho.

Assim, podemos observar o início de uma aproximação destas características negativas à uma compleição fisiológica debilitada, ou seja, certos laboratórios farmacêuticos passam a trazer para o âmbito biológico a falta de produtividade, para que desta forma, possa haver uma solução igualmente biológica, representada no consumo de um determinado medicamento.

Em um sentido conotativo, o anúncio das Pílulas do Abbade Moss (fig.1) relaciona a preguiça a uma dispepsia estomacal. Os vícios morais, presentes neste anúncio, deixam de figurar uma culpabilização pessoal do indivíduo, para serem lançados à interioridade fisiológica. O descompasso advindo da dispepsia é o grande responsável pela improdutividade do sujeito, esteja ele em uma situação de sonolência, debilidade cerebral ou em estado colérico. O anúncio apresenta uma encruzilhada, já que o excesso de trabalho é um possível agente etiológico exógeno que resulta na dispepsia, ao mesmo tempo em que a dispepsia faz com que o indivíduo permaneça "sempre na mediocridade" impossibilitado de "triumphar pela atividade". Desta forma, o excesso de atividade que possibilita o triunfo é também uma causa possível da dispepsia, sendo a única solução para este paradoxo, o consumo do medicamento anunciado, que possibilita o excesso de atividade anulando os males que, mesmo possuindo raízes fisiológicas, tem como resultado prejuízos morais e sociais.

Um importante médico do período, chamado Mário Rangel (1939), também relaciona as causas da dispepsia às certas condições sociais, contudo, apresenta recomendações como: "evitar o excesso de trabalho, as noites em claro", e prossegue

isola e autonomiza o corpo, mas igualmente reforça a vigilância da qual a máquina corporal é objeto” (2013, p.60). 
afirmando que "as preocupações e contrariedades não podem ser proibidas por receita médica, mas elas têm ação bastante nociva sôbre a dispepsia" (p.65).

\section{Figura 2:}

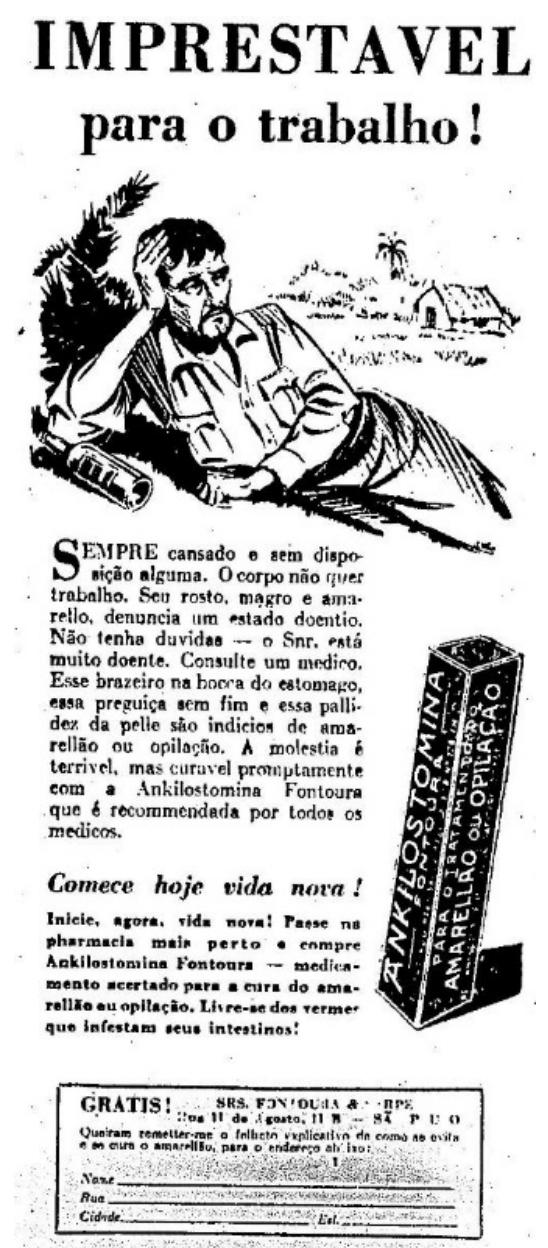

\section{ANKILOSTOMI:VA FONTOURA}

Fonte: O Estado de São Paulo, 09/06/1936.

Em seguida, Rangel aconselha ao médico clínico prescrever uma solução simples de bicarbonato de sódio, sulfato de sódio, cloreto de sódio e água destilada ao paciente em jejum, aliada a uma alimentação equilibrada faria os sintomas da dispepsia desaparecerem 
por completo em 20 a 25 dias. Em casos mais extremos, em que o estado nervoso se acentua, o médico aconselha, além de uma receita médica mais complexa, que:

O estado nervoso secundário, que por si só contribue para manter a dispepsia, será combatido por conselhos de higiene, de repouso físico, moral e sexual; si necessário, estadia no campo ou na montanha, estação hidromineral na Prata. (1939, p.67)

Assim, é perceptível como os anúncios populares são elaborados em conformidade com certos preceitos da clínica médica da época, que assim como a propaganda do Abade Moss, relacionam o desenvolvimento da dispepsia com o excesso de trabalho e o estado nervoso ou colérico. No entanto, o anúncio não visa um tratamento terapêutico longo como o proposto por Rangel - que inclui o período de 20 a 25 dias, ou estadia no campo ou na montanha para recuperação -, o medicamento $O T C^{4}$ deve conter a eficácia e a instantaneidade como símbolos consumíveis.

Certamente, esta relação entre estado fisiológico debilitado e preguiça/indisposição para o trabalho, surge inicialmente na representação do trabalhador rural, acometido pela ancilostomose, febre amarela, doença de Chagas etc., portanto, incapaz de realizar as suas tarefas com vigor e produtividade necessária, conforme as descrições de Monteiro Lobato e, ulteriormente, nos anúncios dos produtos elaborados pelo grupo Fontoura \& Serpe, que além dos anúncios do famoso Biotônico Fontoura, também apresentavam outras propagandas como a da Ankilostomina Fontoura (fig.2). Vemos aqui, similarmente, o descompasso fisiológico produzindo um atraso na força produtiva, por conta de um corpo abalado pelas verminoses que grassavam no campo. Mário Rangel, novamente, estabelece a anemia como possível desdobramento das verminoses rurais, e enfatiza a simplicidade do diagnóstico do doente anêmico.

Ao aproximar-se o anêmico o diagnóstico se faz sem nenhum exame somente pela palidez da pele e das mucosas (conjuntiva ocular, gengivas). Deve-se pensar sempre na verminose. Exame de fezes. O doente mora na roça? E está em contáto frequente com o solo? Na casa em que mora existem instalações sanitárias? Há outras pessoas com verminoses na sua família? (Rangel, 1939, p. 15)

\footnotetext{
${ }^{4}$ Over The Counter é a designação dada a todo medicamento que pode ser consumido sem a necessidade de prescrição médica.
} 
As verminoses causam a anemia, que por sua vez intensifica o estado de indisposição que impossibilita o trabalho, o diagnóstico torna-se prosaico, já que não é necessário nenhum exame detalhado, apenas pela "palidez da pele e das mucosas" e o conhecimento do cotidiano do trabalhador, o médico pode estabelecer a terapêutica necessária.

Nesta época já se tornara prática comum a distribuição de cartilhas de higiene no interior rural. De certa forma, não é possível dizer que os laboratórios farmacêuticos chegam em algum momento a competir com as propostas de saúde pública no campo. Muitos destes laboratórios, desde o começo do século $\mathrm{XX}$, produziam os almanaques brasileiros de educação sanitária que eram distribuídos nas farmácias, e onde faziam ao mesmo tempo a propaganda dos seus remédios. Nestes almanaques constavam informações sobre como evitar doenças, realizar obras como latrinas e poços, entre seções lúdicas de charadas, piadas, calendários e informações astrológicas e, também, os benefícios dos produtos elaborados pelos laboratórios.

Lavrando os benefícios dos medicamentos nos almanaques, os laboratórios atingiam dois alvos principais: os próprios consumidores diretos dos fármacos e os médicos, que lentamente deveriam ser persuadidos a abandonar o método de prescrição de receitas magistrais para receitarem os produtos oficinais.

Portanto, ao menos no campo, a publicidade popular de medicamentos é recebida positivamente, tanto pelo olhar estatal quanto pelo corpo médico, justamente pelo seu caráter "esclarecedor" e pedagógico; tratando-se aqui exclusivamente dos laboratórios que já possuíam algum renome. Entre os principais almanaques estavam o Pharol da Medicina, o Boletim Pharmaceutico da Casa Silva Araújo \& Cia. - publicado trimensalmente, com uma tiragem de 20.000 exemplares -, também o Almanack das Familias do Laboratório Paulista de Biologia, o Almanack de Bristol - produzido pela empresa homônima com sede em Nova York -, e por fim, a Revista Syniátrica do laboratório Orlando Rangel, produzida bimensalmente, com uma tiragem de 16.000 exemplares (CYTRYNOWICZ; STÜCKER, 2007, p. 20). Logo após, temos o famoso Almanaque Fontoura, que surge da parceria entre Monteiro Lobato e Cândido Fontoura, e em 1941 chega a uma tiragem de 10 milhões de exemplares (CHUEIRI, 1990, p. 268), sendo rememorado até os dias atuais por conta da facilidade de compreensão dos preceitos sanitários que chegavam a uma população majoritariamente analfabeta.

Embora a debilidade fisiológica para o trabalhador no campo e para o trabalhador urbano figurasse um impedimento da força produtiva, havia claramente expressões e causas distintas para estes dois segmentos. Como já mencionado, no caso do trabalhador 
rural a gênese de seus males encontrava-se em uma causa estritamente biológica, que embora pudesse ser combatida com medidas profiláticas e higiênicas, a sua etiologia não resultava de um cotidiano de trabalho ou modo de vi

da somente, mas estava muito mais associada a um fatalismo biológico. Embora os agentes patogênicos pudessem ser combatidos, eles não haviam surgido por conta do trabalhador rural, as verminoses eram completamente exteriores a ele, no momento prévio à hospedagem do agente e após a expulsão. Estes sujeitos são inicialmente acusados de serem acometido pela doença em decorrência da miscigenação e, à jusante, pela ignorância das causas e terapêuticas da enfermidade. Neste segundo momento, a doença avança quanto menor o conhecimento, mas os seus agentes, embora não surjam ex nihilo, não são gerados pelas condições produzidas pelos trabalhadores.

Em relação ao trabalhador urbano, as causas das enfermidades que impossibilitam a efusão da força de trabalho encontram-se na própria estrutura que se arregimenta a partir dos resultados obtidos pela força produtiva do trabalhador. Em outras palavras, o excesso de trabalho e as diversas exigências que surgem com o crescimento populacional e a complexidade urbana, possibilitam o surgimento dos próprios agentes etiológicos causadores da debilidade fisiológica do trabalhador da cidade.

Antônio Carlos Pacheco e Silva ${ }^{5}$ aponta para a ubiquidade dos transtornos psicológicos gerados pelo ambiente citadino:

Não há, na realidade, quem se possa vangloriar de não ter, em certos momentos da nossa atribulada existência, apresentado pequenas desordens do sistema nervoso, tais como fobias, idéias obsidentes, leves estados de angústia ou de ansiedade, escrúpulos exagerados ou fases de irritabilidade, as quais, conquanto não ofereçam maior gravidade, não deixam de pertubar a tranquilidade do viver, dificultando o trabalho e provocando transitórios desajustes profissional, familiar e social. (1948, p.6)

E, muito embora Pacheco considere a "atribulada existência" a causa destes diversos estados patológicos do homem moderno, o psiquiatra não deixa de apontar o crescente aumento de trabalho como uma condição imprescindível do sujeito que busca se

\footnotetext{
${ }^{5}$ Além de ser um dos idealizadores do IDORT e o seu primeiro vice-diretor, Pacheco e Silva foi também diretor do Hospício do Juquery, diretor do Departamento de Assistência Geral aos Psicopatas - criado no primeiro ano do Governo Provisório -, participou também da criação das Liga Brasileira e Liga Paulista de Higiene Mental. No livro citado, o psiquiatra versa sobre a totalidade do indivíduo em situações de enfermidades psicossomáticas.
} 
firmar socialmente, evidenciando o porquê de Pacheco e Silva ter sido um dos fundadores do IDORT:

Ao psiquiatra moderno cabe diagnosticar, afastar e tratar os elementos por qualquer razão inadatáveis ao meio, orientar a seleção profissional, aumentar a eficiência no trabalho, coordenar as energias, racionalizar as tarefas e difundir princípios de higiene mental. Em suma: cumpre-lhe ensinar, educar, curar, orientar, prevenir e agir no sentido de tornar a vida do homem melhor ajustada ao ambiente, aumentando o rendimento do trabalho e proporcionando condições de existência mais propícias à felicidade humana. (ibid., p.10)

Assim, educação e cura caminham juntas, educação elaborada pelos difusores dos princípios da higiene mental e defensores da ideologia da racionalização industrialburguesa.

\section{Figura 3:}

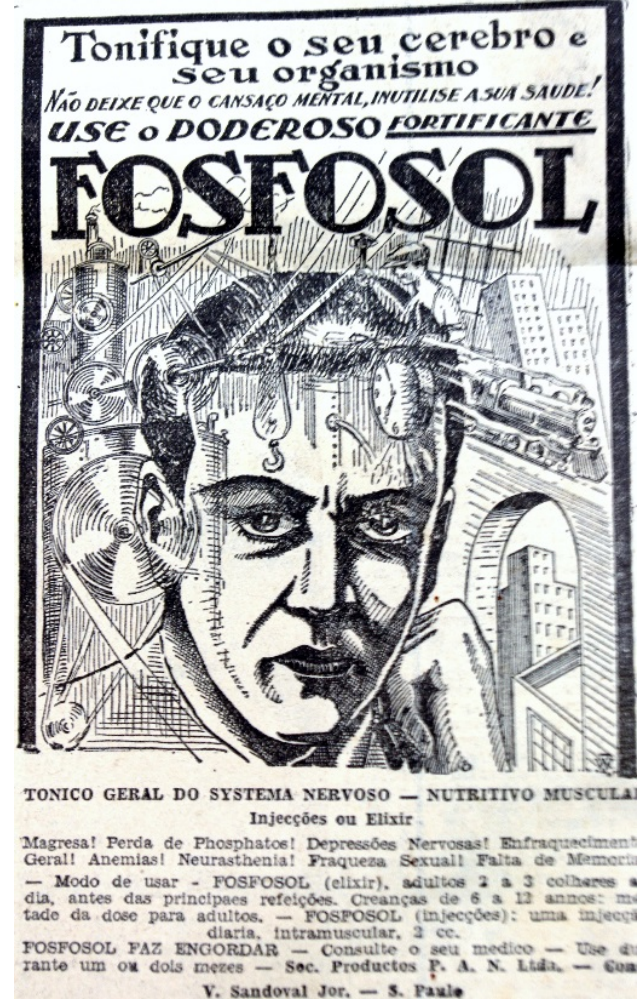

Fonte: Diário da Noite, 03/02/1936.

O psiquiatra então desvela os resultados nocivos provenientes da existência atribulada e coordena as energias e racionaliza as tarefas para ordenar aquilo que se 
excedeu e fugiu ao controle, por conta do próprio excesso de racionalidade. Pacheco e Silva pode então afirmar, em um contexto pós-guerra, que "as aplicações das conquistas científicas, dêstes últimos tempos, à indústria, criaram uma super-civilização que ameaça hoje destruir o próprio homem" (ibid., p. 19).

O anúncio da figura 3 demonstra com clareza este paradoxo da modernização. Em primeiro plano, o rosto abatido denota o evidente cansaço, resultado do trabalho em excesso, já que o anúncio pertence a um fabricante de tônicos gerais. $O$ trem em alta velocidade, os prédios que assomam e cerram a possibilidade de vista do céu, o relógio representando o trabalho cronometrado, o maquinário fabril que ocupa todo o lado esquerdo da imagem e o operário que tem às suas costas uma janela engradada compõe uma cena caótica, que se desenrola sob a parte superior do rosto fatigado, justificando então o uso do medicamento. Note-se a mensagem na parte superior: "Não deixe que o cansaço mental inutilise a sua saúde!", a saúde aqui significa funcionalidade, um corpo sem saúde é um corpo inútil do ponto de vista produtivo. A falta de saúde, que não necessita de maiores esclarecimentos para sua causa, é o que engendra o cansaço mental e outros sintomas que - no canto inferior do anúncio -, devem ser esclarecidos pormenorizadamente devido às implicações sociais que podem acarretar: "Magreza! Perda de Phosphatos! Depressões Nervosas! Enfraquecimento Geral! Neurasthenia! Fraqueza Sexual! Falta de Memoria!".

A magreza não estava inclusa no arquétipo de corpo de um trabalhador conspícuo. Representava a falta de energia, a preguiça, a desmotivação, os ânimos abalados, em suma, a doença; seja esta a tuberculose, a sífilis, as verminoses, o hipertireoidismo, a diabetes etc. A magreza era a enfermidade exposta no corpo diáfano. O médico Vieira Romeiro, em um tratado medicinal da época, apresenta os efeitos da magreza patológica.

O magro hyposthenico é indolente e ocioso. Corresponde ao byotipo longilineo asthenico de Pende. É fraco, sem energia, sempre fatigado, anorexico, atono, inquieto, de formas angulosas, musculatura em geral deficiente.

A magreza esthenica é compativel com uma saude perfeita, ao passo que na magreza asthenica são frequentes varias complicações morbidas, ptoses visceraes, etc., o que, não raro, torna os individuos verdadeiramente incapazes (1941, p. 1173).

O magro classificado como esthenico possuiria uma constituição física vigorosa, predisposto aos esportes, com bom apetite, alerta, infatigável e teria interiorizado o hábito de acordar cedo, mesmo ao dormir tarde da noite. Enquanto que os magros asthenicos ou 
hyposthenicos seriam dotados de letargia e indisposição, e as causas poderiam ser relacionadas a "erros de higiene", como por exemplo, "os excessos de prazeres, excesso de trabalho, vigilias prolongadas, exercicios physicos exagerados, etc." (ibid, p. 1176).

\section{Figura 4:}

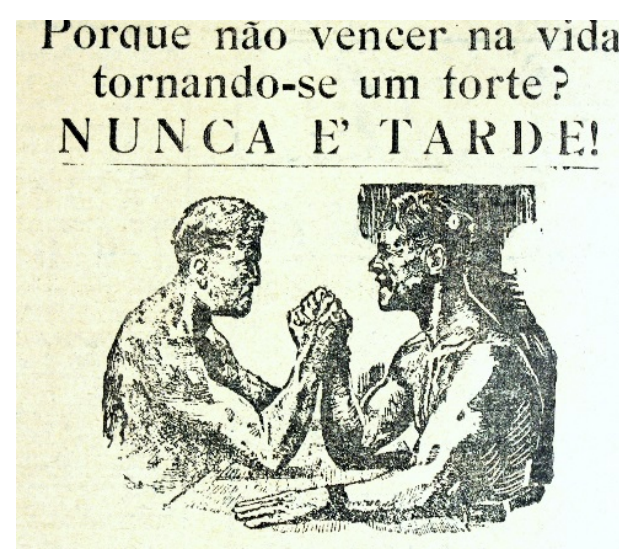

Para transformarmos um organismo debilitado numa nova constituição cheia de vigor, com plena vitalida. de, subjugando, pela resistencia, todo esse cortejo de enfermidades, que nos pro zém da anemia, basta usar

\section{IODOLINO de ORH}

GERADOR ENERGICO D \& SAUDE E DA FORÇA.

Em todas as pharmacia ; e Drogarias do Brasil Fonte: Diário da Noite, 13/05/1933.

\section{Figura 5:}

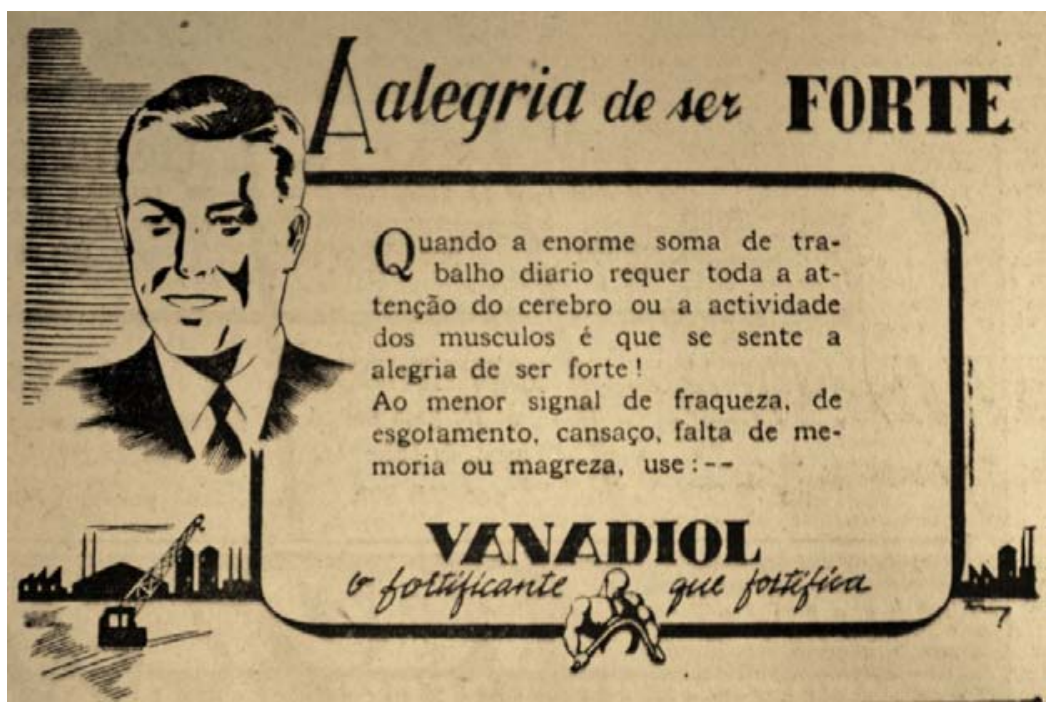

Fonte: Diário da Noite, 09/05/1939. 
Os anúncios das figuras 4 e 5 demonstram a necessidade da robustez corporal como princípio básico para o trabalhador.

O anúncio da figura 4 é claro a respeito da mensagem veiculada: para "vencer na vida" é necessário ser forte. E o receptor da mensagem - referido de antemão pelo emissor como um fraco, visto que não importa o estágio do suposto "fracasso", "nunca é tarde" para a mudança -, ainda pode recorrer a uma última salvação para dotar seu organismo de "plena vitalidade" e consagrar a sua vitória na vida. Os homens na disputa de braço representam um instante, um curto período onde o resultado ainda é indefinido, tendo em vista que seus braços estão em posição vertical idêntica, um momento pausado onde a tensão já está estabelecida, e como na vida, "o mais forte triunfa", no caso aquele que optar pelo medicamento que garantirá o vigor necessário; o que parece ser indicado pelo homem à direita, que sorri, demonstrando que esta disputa não exige um grande esforço físico.

O anúncio da figura 5 enfatiza o caráter essencial da força muscular como instrumento de trabalho, basta notar o logo da marca, que demonstra um homem dobrando uma viga de ferro usando somente a força dos braços. Na linha horizontal deste personagem, nos cantos, vemos as fábricas sombreadas e o guindaste compondo o plano de fundo do anúncio, o que demonstra a necessidade da força para o trabalho fabril, que se confirma indubitavelmente na mensagem ao centro: quando o trabalho exige a "actividade dos músculos é que se sente a alegria de ser forte". Entretanto, no plano principal desta propaganda há também outro tipo de trabalhador, vestido de terno e gravata, sorridente e com os cabelos arrumados, muito diferente dos homens disputando a queda de braço na propaganda anterior, e de tantos outros presentes nos anúncios de fortificantes. A alusão é de que a força do organismo é também força intelectual, a "atenção do cérebro" e a "actividade dos músculos" são inextricáveis, assim como "a falta de memória ou magreza" são sinônimos. 
Figura 6:

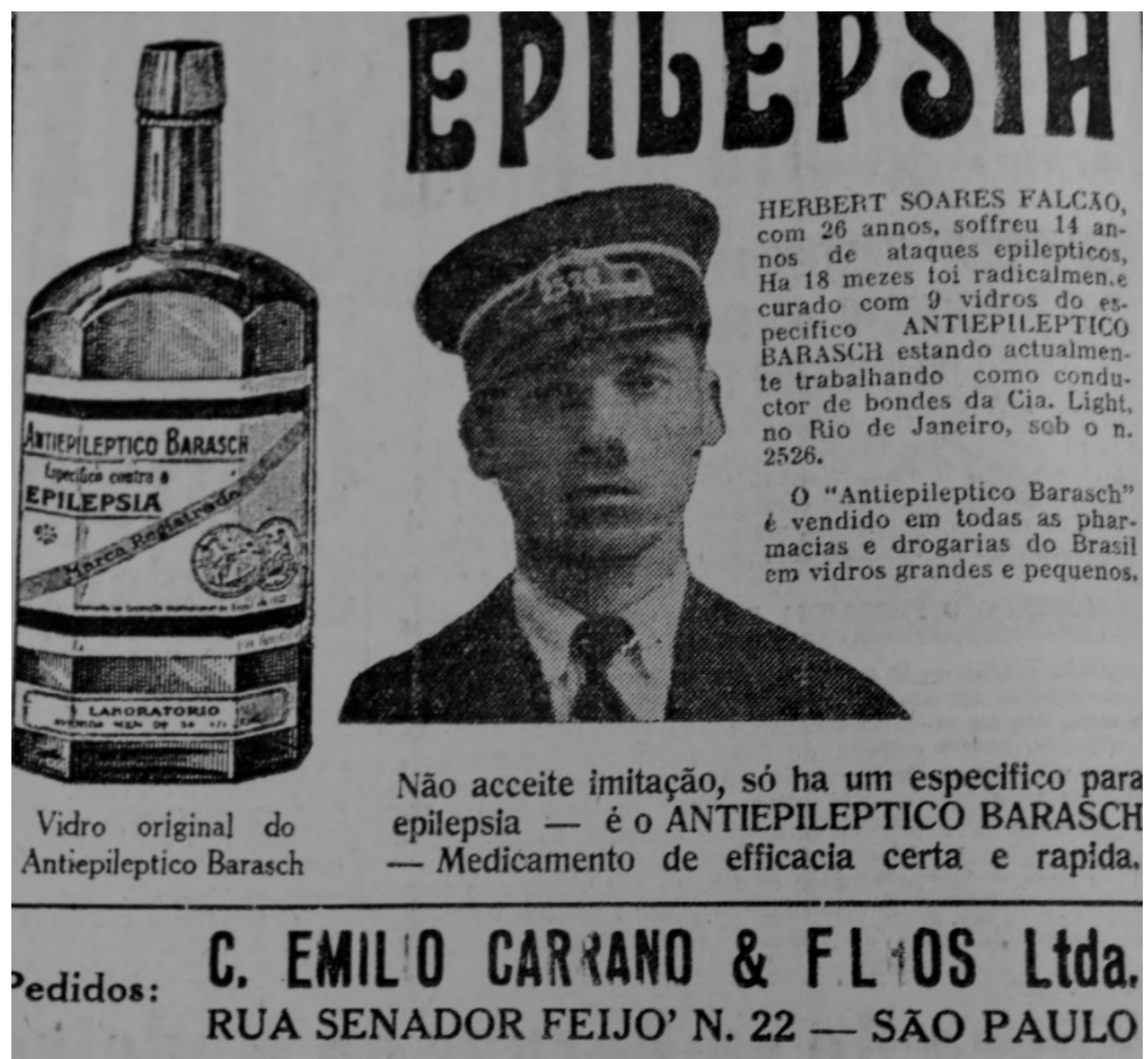

Fonte: Diário da Noite, 08/07/1935.

Também no anúncio da figura 3, a magreza encontra-se na mesma esteira de sintomas que as depressões nervosas, a neurastenia e a falta de memória. Já não é somente a força de trabalho braçal que deve ser preservada, mas a memória, a concentração e as faculdades intelectuais em geral, para necessidade da garantia da venda da força de trabalho no mercado. E a compleição física robusta, forte e viril torna-se uma premissa para o pleno desenvolvimento das atividades mentais ${ }^{6}$.

\footnotetext{
${ }^{6}$ Outra interpretação deste anúncio também poderia ser aparentemente possível. Em que o homem de terno figurasse como algum funcionário, com um cargo hierárquico mais elevado dentro da estrutura fabril, por isso a distinção das faculdades intelectuais. No entanto, a marca Vanadiol, ao longo de todo o percurso da pesquisa demonstrou a veiculação de mensagens simples, diretas e com um forte apelo às questões da masculinidade e virilidade, o que o seu slogan tautológico ajuda a confirmar. Algumas propagandas ajudam nesta exemplificação, Diário da Noite, 01/01/1935: Magros e Fracos - E’ um fraco? Teme a tuberculose? Vanadiol é
} 
Devemos lembrar que grande parte da publicidade dos medicamentos OTCS, dizia respeito a um amplo número de descompassos psicológicos, nomeados como: neurastenias, depressões nervosas, debilidades nervosas, fraqueza cerebral, falta de memória, insônia e até mesmo a epilepsia. Todos estes sintomas estavam inseridos em um contexto de impossibilidade de realização de um determinado serviço ou compromisso social.

Um curioso anúncio dos Antiepiléticos Barasch (fig. 6) demonstra este caráter de cura milagrosa dos "nervos", proporcionada pelo medicamento.

Utilizando o método testimonial, este anúncio lavra a conquista de um jovem que sofreu durante 14 anos de epilepsia. Agora, curado pelo medicamento Barasch, não apenas curou-se consumindo um vidro do medicamento a cada dois meses, como a confiança sobre a idoneidade do antiepilético possibilitou que o consumidor conseguisse um emprego - improvável para um epilético -, como operador de bondes pela Cia. Light.

Justamente por representarem essa exigência de um esforço intelectual do trabalhador urbano, ao mesmo tempo em que o espaço citadino constituía-se como ambiente que colocava o indivíduo à prova em todos os instantes do cotidiano, as enfermidades nervosas começam a figurar como um grande problema para os habitantes da cidade. O médico Mário Rangel classifica então a neurastenia da seguinte forma:

Todos os casos de fatigabilidade anormal e de astenia sem causa orgânica aparente. Na neurastenia há sempre uma relação direta entre a causa nervosa (emoção, exgotamento) e o efeito orgânico, o que permite diferenciar nitidamente do nervosismo, considerado simples eretismo nervoso.

A neurastenia provem sempre de emoções desagradáveis, desgostos, trabalho intelectual excessivo. A primeira medida será afastar a causa. (Rangel, 1939, p. 99)

Em seguida, o médico propõe duas formas distintas de terapêutica. A primeira seria um "tratamento higiênico", a mudança de ambiente da cidade para o campo, para as montanhas, para que o indivíduo se encontre em um ambiente diverso daquele que está habituado, distante da família nesta fase inicial, o doente deverá intercalar atividades

indicado para as pessoas assim enfraquecidas, porque é um poderoso tonico do pulmão fraco. Qualquer pessoa, póde tomar o Vanadiol para fortalecer-se e engordar.

Diário da Noite, 01/06/1934: Para os fracos, magros e nervosos. Vanadiol: o fortificante que fortifica.

Diário da Noite, 25/01/1935: Preguiça - Anemia: Homens sem energia, moças desanimadas. A anemia atraza a vida porque rouba as forças para o trabalho. O Vanadiol augmenta os globulos sanguineos e VITALISA o sangue enfraquecido. 
"alternando a leitura, a escrita, o passeio, os esportes moderados". Outra perspectiva de cura seria o tratamento com medicamentos, baseado em "tônicos vegetais, noz vômica ou seus alcaloides, estricnina, 1 ampola de 0,001 por dia, injeções arsenicais, fosfatos e glicerofosfatos de sódio, cálcio e magnésio" (ibid., p. 99).

Esta segunda forma de tratamento insere-se no curto tempo da cura que busca instantaneidade, sendo também a técnica utilizada pelos anúncios populares, e que atualmente é o método de cura hegemônico, o da instantaneidade e do total "controle" do indivíduo sobre o seu corpo. Assim, promulga-se, segundo Fernando Lefevre, uma "economia simbólica dos tempos demorados da saúde" (1991, p. 70), obliterando qualquer questionamento acerca das possíveis mudanças nas estruturas sociais e produtivas que cercam o campo da cura. O medicamento como o "recurso fácil e rápido que permite o imediato restabelecimento da tarefa" (ibid., p. 72), oculta as contradições sociais que cindem os dois tipos possíveis de terapêutica, de um lado o lento "tratamento higiênico" e, do outro, a síntese de substâncias, escondidas atrás das nomenclaturas químicas, que propulsionam o indivíduo novamente para o seu local social.

Os largos tempos da saúde, necessários para que as mudanças ocorram, não são questionados. O tempo para a mudança de comportamentos em relação à saúde, o tempo para que mudanças estruturais da cidade ocorram e se efetive uma diminuição das doenças que crescem em seu bojo, o tempo para que ocorram as mudanças em relação à salubridade no ambiente de trabalho. São todos suprimidos, em decorrência de uma lógica de competividade que incute nos indivíduos o medo da substituição, caso o tratamento tenha um período demasiadamente prolongado. A ideologia da eficiência produtiva reconhece o tempo da cura, apenas como tempo "perdido" e, conforme apontou Foucault, o capitalismo que se desenvolve a partir do século XIX socializa o corpo como um objeto em função da força de trabalho, em que o controle não mais se efetua somente pela consciência, mas também "dentro e com o corpo" (1981, p. 405).

Ademais, José Palmério ${ }^{7}$ declara serem recorrentes os casos em que os trabalhadores têm o acesso às consultas médicas dificultadas pelos seus próprios chefes, que temem prejuízos caso tenham que arcar com as despesas.

Dirigentes de cooperativas, beneficencias e, tambem, muitos patrões chegam mesmo a dificultar, quando não a obstar as consultas medicas,

\footnotetext{
${ }^{7}$ Psiquiatra do período e um dos primeiros estudiosos a sistematizar os desenlaces do desenvolvimento da indústria farmacêutica no Brasil.
} 
temendo que o peso do receituário recaia sobre os cofres da Instituição a que pertencem ou venham individar o empregado, comprometendo seu sossego e sua capacidade de trabalho. A media das consultas mesmo nos serviços gratuitos é muito baixa em geral. (Palmério, 1942, p. 54)

A despeito de uma nova legislação trabalhista ter sido promulgada em 1934, em que a definição de acidente de trabalho se amplia, exigindo uma maior cobrança do empregador, que deveria responder agora ao Ministério do Trabalho, Indústria e Comércio (MTIC), a possibilidade de interpretações sobre a legislação continuava a desfavorecer o trabalhador. Certas doenças causadas pelo contato com chumbo, fósforo, sílica etc., já se aproximavam de um laudo mais concreto e próximo da realidade, entretanto, as doenças consideradas atípicas, chamadas de mesopatias, que não possuíam uma relação causal direta com o trabalho exercido, davam margem para várias interpretações distintas, que frequentemente favoreciam o empregador.

A própria tuberculose era considerada uma doença social e não profissional, sendo muito difícil um trabalhador da época conseguir convencer os juízes sobre a relação entre a obtenção do bacilo de Koch com o ambiente insalubre de trabalho, em que existisse mau ventilação, mudanças bruscas de temperatura, fadiga crônica decorrente do excesso de trabalho etc. A historiadora da saúde, Anna Beatriz de Almeida, aponta como os patrões e a própria perícia técnica do MTIC, consideravam os casos de tuberculose como resultantes do modo de vida dos trabalhadores.

"A tuberculose é uma doença social", esta era uma afirmação recorrente, tanto na defesa dos acusados, os patrões, quanto nas sentenças dos juízes e, como tal, não caberia responsabilizar os patrões pelo seu acometimento. Não teria havido algum caso de tuberculose na família do operário? Quando ingressou no serviço, gozava realmente o trabalhador de boa saúde? Era o trabalhador uma pessoa de "bons costumes" ou havia indícios de ter uma "vida desregrada", "imprudente"? (2006, p.204)

É sobre o próprio sujeito que recai a responsabilidade sobre a sua saúde, e a utilização de medicamentos OTCS surge como uma possível garantia da venda da força de trabalho. 


\section{Figura 7:}

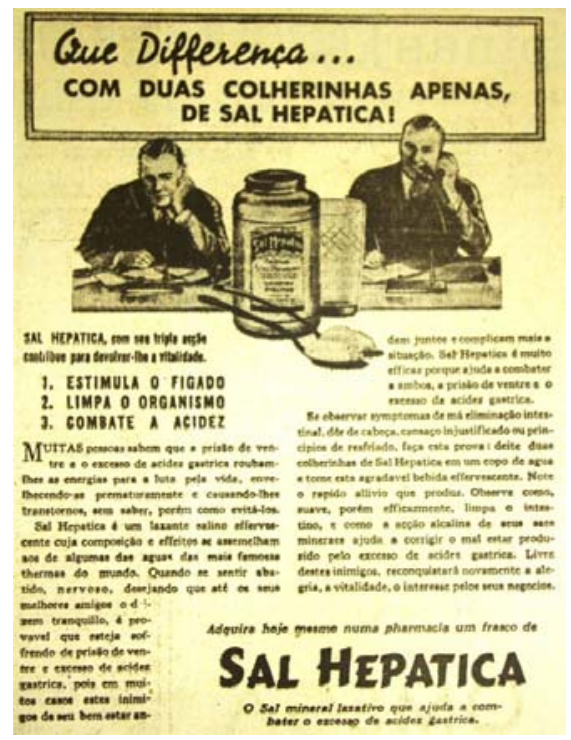

Fonte: Diário da Noite, 05/05/1939.

Os remédios eram anunciados não apenas para a restituição e garantia da saúde, mas apareciam também como propulsores da carreira do indivíduo. As figuras 7 e 8 demonstram a instantaneidade do efeito do medicamento, não em direção ao bem-estar do sujeito, mas para a restauração do desempenho da força produtiva. Na figura 7, vemos a restituição instantânea da disposição para o trabalho, apenas com "duas colherinhas" do referido medicamento.

\section{Figura 8:}

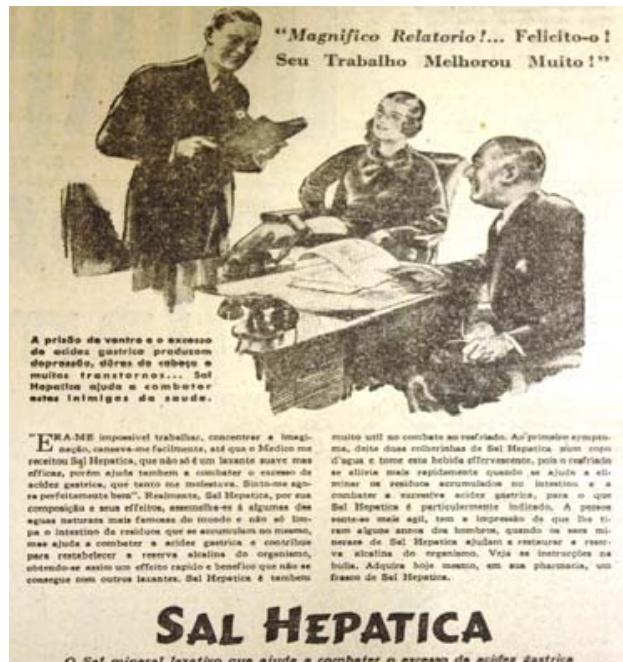

Fonte: Diário da Noite, 26/05/1939. 
$\mathrm{Na}$ figura 8 - e poderíamos pensa-las sequencialmente, referindo-se ao mesmo trabalhador -, o medicamento não apenas cura a indisposição, como deixa de ser um coadjuvante na prática do trabalho, para ser o protagonista que possibilita o aprimoramento da função, e o consequente elogio do superior ao trabalho produzido.

Lefevre (1991) utiliza o conceito de "resolução tecnológica da vida", para se referir à utilização dos recursos disponibilizados, perpetuamente pela ciência e a técnica, para configurar outras formas de se estar no mundo. Os remédios seriam então "próteses químicas", criadas para preencher seus respectivos "vazios químicos", que se aprofundam conforme a constituição social da necessidade de saúde se intensifica.

A saúde, no âmbito da "resolução tecnológica", surge como forma de reposição de "peças danificadas" deste corpo mecanizado. Por isso, as próteses do bom-humor, da concentração, da força muscular, da disposição, do sono tranquilo etc., devem estar constantemente disponibilizadas em um contexto social que "desgasta" as variadas parcelas da identidade humana. A "resolução" opera desta forma com pares de oposição simplificados, o moderno contra o antigo, concentrado e disperso, forte e fraco, rápido e lento (LEFEVRE, 1991, p. 65). E, como o discurso de Francisco Salles de Oliveira, citado inicialmente, apregoa ser "necessario que todos os serviços funccionem harmonicamente e se completem e entrozem como se fossem peças de um machinismo" $(1937$, p. 16), então, os medicamentos seriam um dos elementos de garantia da atividade ininterrupta deste sistema harmonioso.

A harmonia para produção e os remédios para adequação ao trabalho, retiram qualquer suspeita que possa recair sobre as relações sociais contraditórias. As enfermidades e os descompassos resultam de fatores atemporais, a sociedade em crise é um dado em si, impenetrável. Portanto, as doenças não podem ser o resultado desta constituição social, mas antes, a etiologia encontra-se na falha de decisão de indivíduos isolados, já que o excesso de trabalho, o caos urbano, a insalubridade fabril etc., são fixados como partes indissociáveis do todo, rígido e inexorável. Desta forma, o espaço de atuação possível fica relegado à conscientização sanitária do indivíduo, a atuação incompleta dos órgãos públicos de saúde e a decisão pelo consumo dos medicamentos comercializados abertamente.

\section{REFERÊNCIAS BIBLIGRÁFICAS}


ALMEIDA, Anna Beatriz de Sá. Doenças e trabalho: um olhar sobre a construção da especialidade medicina do trabalho. In: NASCIMENTO, Dilene Raimundo et al. (orgs.). Uma História Brasileira das Doenças - II Seminário. Rio de Janeiro: Mauad, 2006.

ANTONACCI, Maria Antonieta. A vitória da razão (?) - o IDORT e a sociedade paulista. São Paulo: Ed. Marco Zero, 1993.

CHUEIRI, Carlos R. E, no princípio, era a verba... In: BRANCO, Renato Castelo; MARTENSES, Rodolfo L.; REIS, Fernando. História da propaganda no Brasil. São Paulo: T.A. Queiroz, 1990.

COURTINE, Jean-Jacques. Decifrar o corpo - pensar com Foucault. Petropolis: Ed. Vozes, 2011.

CYTRYNOWICZ, Monica; STÜCKER, Anando. Origens e trajetórias da indústria farmacêutica no Brasil. São Paulo: Narrativa Um, 2007.

FOUCAULT, Michel. O nascimento da medicina social. In: Microfísica do poder. Rio de Janeiro: Graal, 1981.

LEFEVRE, Fernando. O medicamento como mercadoria simbólica. São Paulo: Ed. Cortez, 1991.

OLIVEIRA, Francisco de Salles. Finalidades da saúde pública. In: Racionalização e medicina - palestras realizadas pelos diretores do IDORT perante a Sociedade de Medicina e Cirurgia de São Paulo. São Paulo: Graphica da "Revista dos tribunaes", 1937.

PALMÉRIO, Jose. O custo dos remédios e economia medico-farmaceutica. São Paulo, 1942.

RABINBACH, Anson. The human motor: energy, fatigue, and the origins of modernity. Berkeley: University of California Press, 1992.

RANGEL, Mário. As consultas de todos os dias. Rio de Janeiro: Tip. Irmãos Di Giorgia \& C., 1939.

ROMEIRO, Vieira. Tratado de pathologia medica. Rio de Janeiro: Ed. Guanabara, 1941 (tomo I).

SILVA, A. C. Pacheco. A psiquiatria e a vida moderna. São Paulo: Edigraf, 1948.

VIGARELLO, Georges. "Ciência do trabalho" e imaginário do corpo. In: Projeto História, n. 34 - tecnologia, cotidiano e poder. São Paulo: EDUC, junho/2007.

Jornal O Diário da Noite.

Jornal O Estado de São Paulo. 